\title{
IODINE AS AN INDICATOR OF SAPWOOD AND HEARTWOOD.*
}

\author{
H. W. EADES
}

$\mathrm{T}^{\mathrm{s}}$

HE LIMITS of sapwood and heartwood are, as a rule, readily apparent to the eye on a newly cut cross-section of a $\log$ cut from a healthy, normal tree. The outer annual rings, comprising the living elements of the trunk and its water-carrying tissue, are yellowish or creamy. white in colour, and contrast with the definitely darker region of the heartwood in the inner portions of the log as, for example, in Douglas fir, yew, and Western red cedar. With some of our woods, however, such as poplar, willow, the spruces, the true firs, and Western hemlock, the heartwood has the same light colour as the sapwood, so that no definite line of demarcation between the two is apparent.

Although it is true that some woods have a higher proportion of sapwood to heartwood than others, this proportion is by no means constant within each wood species, and may vary according to site or exposure, or an individual tree may show differences according to the position of measurement in the tree. For example, rapidly grown trees, or trees grown in the open, have a larger proportion of sapwood than those grown in less open stands. In the latter type of stand, while the number of rings contained in the sapwood are usually greater, the volume of the sapwood is less than in open stands.

In Douglas fir poles or piling which are to be impregnated with creosote, the presence of a certain depth of sapwood becomes necessary, since the creosote penetration is largely confined to the sapwood, and the creosoted portion must be thick enough to give adequate preservation. Material for this purpose usually comes from thick stands of slow-grown timber, where natural pruning has trimmed off the lower limbs, leaving a suitably tall, straight, slim trunk. Inspection and rejection of pole material often hinges, therefore, upon the thickness of the sapwood. As a rule, little difficulty is experienced in measuring the sapwood, even though Douglas fir normally has only a narrow sapwood band, because a cross-section readily shows up the colour contrast between sapwood and heartwood. Recently, nevertheless, companies cutting Douglas fir poles and piling in certain areas have found diffculty in measuring the sapwood, because of lack of colour differentiation between sapwood and heartwood, both these portions of the tree showing the uniform, yellow straw colour which is characteristic of

"Contribution from the Forest Products Laboratories of the Dominion Forest Service, Department of Mines and Resources. 
"yellow fir." In some cases, it was found that such material had been rejected as containing no sapwood whatever.

Specimens of the material in question were brought to the Vancouver Laboratory of the Forest Products Laboratories of Canada with the request that sapwood and heartwood be differentiated in the specimens, and that we should devise some method by which pole and piling inspectors could determine the extent of the sapwood in Douglas fir in doubtful cases. On examination, the specimens were found to have been cut from extremely slow-grown trees, so that the annual rings in the outer portion underneath the bark measured as many as one hundred to the inch. The whole of the cross-section from inner bark to pith was of a uniform straw colour, with no apparent differentiation between sapwood and heartwood.

With many woods it will be found that in process of time the colour of the heartwood deepens, as a result of an oxidation process, while that of the sapwood does not, thus helping to delimit the boundaries of each on a cross-section, but, although the specimens provided had been seasoning for several months, there was no contrast apparent due to oxidation changes. This demonstrated the uselessness of applying natural colour changes produced in the course of seasoning as a method of delimiting sapwood in doubtful cases of this nature.

Even under laboratory conditions we were aware of no apparatus or procedure which could, with any rapidity, differentiate sapwood from heartwood in doubtful cases where the colourations were confusing to the eye. Only with the exercise of a great deal of time and patience can the variations in the positions of the bordered pit tori be observed under the microscope, and this miscroscopic feature represents the only known variation in the cellular structure of sapwood and heartwood. Nor are there any detectable differences in the mechanical reactions of strength-testing instruments, from the point of view of the hardness functions of sapwood and heartwood within an individual species, which could be used as a guide, since the strength functions of normal sapwood and heartwood are identical.

Faced with the lack of any ready-made, handy method for solving this problem, consideration was given to devising one. Uniformity of colour in the cross-sections of the specimens indicated that the usual infiltration of tannins, anthocyanins, and other substances of complex chemical origin which give colour to heartwood, was more or less uniformly present throughout both sapwood and heartwood. There was no reason to suppose, however, that the starches, sugars, and other carbohydrates normally present in sapwood, and comparatively absent in heartwood, would be as uniformly distributed. Since the most characteristic reaction of starch is the blue colour 
with iodine, it was thought that iodine might be used to distinguish sapwood from heartwood.

Specimens of the Douglas fir piling in question, containing uniformly coloured sapwood and heartwood, were cut into discs and the cross-sections planed smooth (subsequently we found that saw cut sections, cut with a fairly fine saw, are more suitable for a rapid test). Some commercial tincture of iodine, of the sort obtainable at any drug store, and usually consisting of a $21 / 2$ per cent. solution of iodine in alcohol, was diluted with an equal amount of water, making about a $1 \frac{1}{4}$ per cent. solution. By means of an eye dropper, the diluted iodine solution was placed, a drop at a time, in a series of contiguous drops, along several radii on each cross-section. Within half an hour the iodine drops on the outer rings turned definitely blue or blue-black, while those applied to the inner heartwood remained unchanged in colour. By this colorimetric means, those annual rings which produced a change in the colour of the iodine, and those which did not, were readily differentiated. Where a drop overlapped both sapwood and heartwood, a portion of the drop changed colour on soaking into the wood, while the remaining portion of the drop remained unchanged in colour. As a check, the same procedure was applied to sections containing definitely marked sapwood and heartwood areas, and the change in colour of the iodine solution was found to stop definitely at the limit of the sapwood area on each cross-section. It was considered, therefore, that this test forms a useful, practical means of determining the boundaries of the sapwood in Douglas fir.

Since quite definite results were obtained with Douglas fir, the experiment was carried a little further, so as to include other woods, but the results varied, and in no case were they as definite or as uniform as those obtained on Douglas fir.

First we tried Western red cedar. Certain specimens of this wood in the form of house siding, containing streaks of white wood on one edge, had been brought to the laboratory for an opinion as to whether the white wood was sapwood, or simply light coloured heartwood. In a commercial shipment of this material, a considerable proportion had contained these white streaks. Because of the known lack of durability of sapwood, the cedar grading rules do not permit its inclusion in material where durability or resistance to decay is required. The matter was, therefore, of some commercial importance. The material was quite dry and well seasoned.

Application of $21 / 2$ per cent. and $11 / 4$ per cent. iodine drops produced no comparative results, whereupon a combination of potassium iodide and iodine tincture, usually considered to be a more delicate test for starch than straight iodine, was used. The proportions used were 2 parts of potassium 
iodide solution ( 2 per cent. in water) and 2 parts of iodine $(21 / 2$ per cent. in alcohol) to 100 c.c. of water. This resulted in a definite blue-green colour in the white wood, with no change of colour in the heartwood. We therefore considered it justifiable to call the white wood sapwood. Application of this combined solution to naturally differentiated sections of cedar sapwood and heartwood which were freshly cut produced the same colour contrast, as did applications also of $21 / 2$ and $1 \frac{1}{4}$ per cent. iodine.

The tests were then applied to some other British Columbia woods, namely, Western alder, Western maple, Western hemlock, true fir (Abies amabilis), and Sitka spruce. In certain cases where the colour reaction with iodine was not sufficiently rapid or definite, the potassium iodide and iodine combination was used, but the results obtained with this solution were on the whole no more satisfactory than where straight $2 \frac{1}{2}$ per cent. iodine tincture or $1 \frac{1}{4}$ per cent. iodine solution were applied. Of the woods used, the only exception was Western red cedar in the dry condition. Since iodine gave as good results as potassium iodide, plus iodine, and is more readily obtained, it is recommended in place of the latter for general purposes of this nature, in circumstances where a simple, rapid test is desired. When $21 / 2$ per cent iodine will not work, $11 / 4$ per cent. iodine often will.

Definition between heartwood and sapwood, with a blue reaction to iodine, was obtained, with somewhat less definition and rapidity than on Douglas fir, on Western maple, Western alder, and amabilis fir. On Western hemlock and Sitka spruce, iodine produced a sepia brown colour on the sapwood, but only after a considerable lapse of time, and no rapid test was developed for delimiting sapwood in these two woods, which is unfortunate, in that their sapwood and heartwood are normally of a similar colour.

The absence of a definite blue or blue-black colour change in the sapwood of these two woods, and the incidence of a change from the normal colour of the tincture to a brown colour, tending to sepia, led to the conclusion that they contained little or none of the starches, but, in place of starch, dextrins or dextroses, which are starches in the process of breaking down into sugar (iodine produces a brown coloration on dextrose).

A complete list of the tests made is appended hereto. 


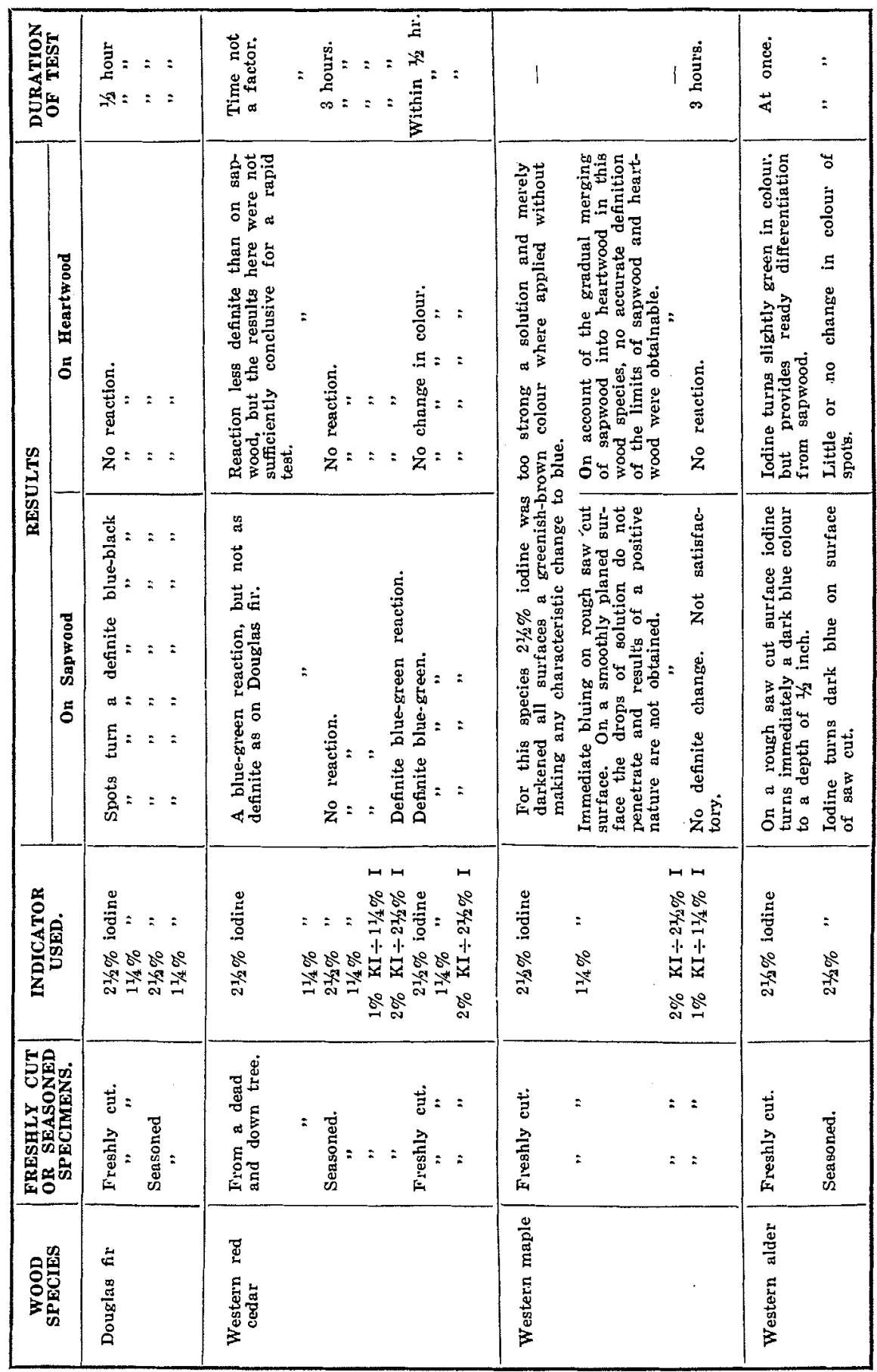




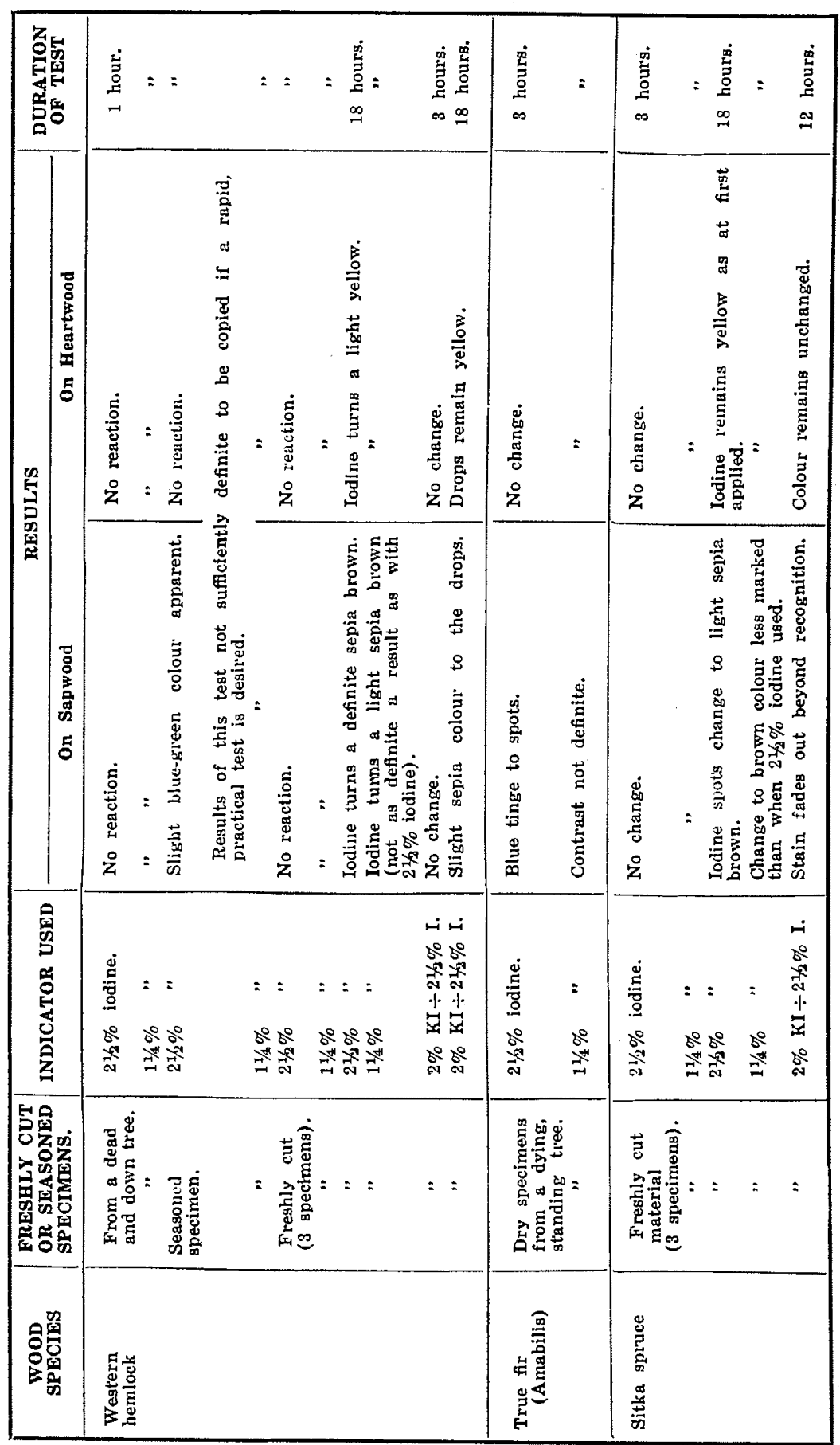


SUMMARY AND PRACTICAL APPLICATION:

When iodine drops are applied to the cross-section of a log or sections cut therefrom, along radial lines, the changes in colour of the drops form a useful method of determining the limits of sapwood and heartwood in certain woods.

Of the woods tested, it is felt that the method may be recommended as of definite, rapid, practical value in the case of Douglas fir, the sapwood of which appears to contain more starch than the others. The method also works satisfactorily upon Western red cedar, although there will seldom be difficulty in distinguishing sapwood from heartwood in this wood species. It also works satisfactorily upon Western maple and Western alder. With Western hemlock and Sitka spruce, woods with a sapwood colour normally approximating that of heartwood, and upon which a workable procedure would have been of value, the spot test as developed in this little series of experiments proved to be unsatisfactory, chiefly because of the time requirement.

Freshly cut or green wood allowed more definite results than dry or partly dry wood in all cases, and a saw cut with a fairly fine saw works better than a smooth cross-section. Straight tincture of iodine (a $21 / 2$ per cent. solution in alcohol), as it comes from the druggist, is generally satisfactory. If it is found too strong, it should be diluted to half this strength.

Laboratory workers and others who have facilities for experiments of this kind may find the idea useful on woods other than those mentioned where identification of sapwood and heartwood is desired. In such case the use of several solutions simultaneously would be advantageous, as, for example, $21 / 2$ per cent. iodine, $11 / 4$ per cent. iodine, 2 per cent. potassium iodide plus $21 / 2$ per cent. iodine, and 1 per cent. potassium iodide plus $1 \frac{1}{4}$ per cent. iodine.

No attempt was made during these experiments to correlate the time of felling the tree, i.e., whether during the winter resting period or when the tree is in leaf-with the efficacy of the iodine spot test, but it is realized that the time of the year at which a tree is felled probably has an important relation to the starch content of some species. While the change of colour from iodine to blue may safely be taken to indicate starch, and, therefore, sapwood, it is possible that the absence of blue colour does not invariably indicate heartwood, since seasonal variations in the starch content of the sapwood in an individual tree may occasionally reduce the starch content to a point low enough to prevent a colour reaction. Nevertheless, where a definite line of demarcation, coinciding, for example, with the limit of a growth ring, between coloured and colourless wood, is produced after application of iodine, the wood on either side of the demarcation line may, of course, be considered sapwood and heartwood, respectively. 


\section{REFERENCES :}

Sinnott, E. W. Botanical Gazette, Aug. 1918, pages 162-175. Factors determining character and distribution of food reserve in woody plants.

Preston, J. F. and Phillips, F. J. Forestry Quarterly 9:232, 1911. Seasonal variation in the food reserve of trees.

Campbell, W. G. Biochemical Journal, vol. XXIX, No. 5, pp. 1068-1080, 1935 The starch and related polysaccharides of certain hardwoods. 